These authors employ "reticulosis" as a blanket term to embrace Hodgkin's disease, lymphosarcoma and follicular lymphoma, myeloma, polycythaemia vera, reticulum cell sarcoma, and various types of leukaemia. Of the total of 774 patients studied $26 \%$ developed neurological syndromes. About half of these were due to local deposits of neoplastic tissue, most of them involving compression of the spinal cord or nerve roots. Of the non-metastatic complications, half (about $25 \%$ of all neurological manifestations) were caused by infections, presumably related to impaired immunological reactions, herpes zoster being particularly common. Only three patients developed progressive multifocal leucoencephalopathy - a newly described disease ${ }^{2} 3$ which appears to be related to viral infection. ${ }^{4} 5$ The prevalence of cerebrovascular lesions was surprisingly low $(18 \%$ of all the neurological syndromes) though Currie and Henson acknowledge that this may be because they had no information on terminal vascular attacks at home.

The remaining neurological syndromes were a mixed group of metabolic disorders (such as uraemia, hepatic encephalopathy, and hypercalcaemia) and miscellaneous conditions such as entrapment neuropathies and amyloid neuropathy. Compression of the spinal cord and nerve roots was particularly common in myeloma, infection in Hodgkin's disease, and cerebral haemorrhage in acute leukaemia. Haemorrhage was generally associated with thrombocytopenia, while occlusive vascular disease was confined to polycythaemia vera. It is notable that intracranial metastatic deposits were very unusual in this series of patients. The low incidence of meningeal infiltration in acute leukaemia was especially surprising, and contrasts with that in other reports. $^{6}$

As treatment has been improving, neurological complications of haematological neoplasia are being encountered more frequently because of extended survival. ${ }^{7}$ Moreover, neurological symptoms may arise from lesions outside the nervous system. For example, deafness, tinnitus, or vertigo have been reported in 27 out of 100 consecutive patients with leukaemia, ${ }^{8}$ the cause being haemorrhage, lymphoid hyperplasia, or infection affecting the ear.

One aspect of this subject which is becoming increasingly important is the damage done to the nervous system by modern therapy. Vincristine neuropathy, radiation myelopathy, and cerebral haemorrhage due to thrombocytopenia induced by cytotoxic agents are all beginning to contribute appreciably to the neurological complications seen in these disorders. Similarly infection of the nervous system will probably increase as immunosuppressive drugs are employed in higher doses and more potent combinations. It has been suggested that intracranial lymphomas may themselves be produced by immunosuppressive therapy, for their prevalence is higher than expected in patients who have received transplants. ${ }^{9}$ Thus therapeutic advances against haematological neoplasia may enlarge rather than reduce the pattern of neurological complications.

1 Currie, S., and Henson, R. A., Brain, 1971, 94, 307.

2 Richardson, E. P., New England fournal of Medicine, 1961, 265, 815.

${ }^{3}$ Richardson, E. P., in Remote Effects of Cancer on the Nervous System, ed. W. R. Brain and F. H. Norris, p. 6. New York, Grune and Stratton, 1965.

4 Silverman, L., and Rubinstein, J. L., Acta Neuropathologica (Berlin), $1965,5,215$.

5 Woodhouse, M. A., et al., Brain, 1967, 90, 863.

' Pierce, M. I., in Pediatric Clinics of North America, 1962, 9, 425.

7 Evans, A. E., Gilbert, E. S., and Zandstra, R., Cancer, 1970, 26, 404

8 Shanbrom, E., and Finch, S. C., Yale fournal of Biology and Medicine,

1958, 31, 144.
Schneck, S. A., and Penn, I., Lancet, 1971, 1, 983.

\section{"Challenges for Change"}

There will be no overnight transformation of the National Health Service on 1 April 1974. Any improvement in the Service as a result of the forthcoming reorganization ${ }^{1-4}$ will take place gradually, and it could be five to ten years before the full effects of the reforms are felt. But is what the Government has proposed in its consultative documents enough? Judging from the essayists who have contributed to Challenges for Change 5 (see Supplement, 6 November, p. 27; 13 November, p. 31; and this week, p. 39) the answer is certainly not. In their introduction to the book Dr. John Revans and Mr. Gordon McLachlan put forward four proposals which specially merit the profession's attention: (1) "to develop a philosophy of health services where the rights, the duties and the expectations of every individual should be clearly set out without political or professional bombast;" (2) to define "a series of objectives for the N.H.S., including a theory on administration to attain them;" (3) the monitoring of the quality of health care; and (4) the development of a coherent manpower policy.

Overshadowing all these issues, however, is the question of finance. Earlier this year in a memorandum of evidence ${ }^{6}$ to a parliamentary committee investigating health service expenditure the Department of Health lifted the curtain on how it produces the annual estimates for the health budget. To anyone with experience of the in-fighting for funds at all levels of the National Health Service the impression the memorandum gives of impreciseness in the estimating procedures will occasion no great surprise. Existing commitments, inflation, and pay increases seem largely to determine the annual budget. Events dictate policies, with an occasional shift of emphasis prompted by a public outcry about this or that health problem. The Department in explaining to the parliamentary committee the difficulties involved in forecasting its annual budget gives as the main reason "the existence of clinical freedom," claiming that this "substantially reduces the ability of the central authorities to determine objectives and priorities and to control individual facets of expenditure."

The quid pro quo for this clinical freedom for doctors is their collective duty to suggest improvements in health care, within the resources likely to be available in the next few years. In his essay Professor C. T. Dollery suggests how this might be done. He proposes an advisory service covering the whole N.H.S., comprising-initially - a health care committee and a health care research board. The board he sees as conducting comparative experiments in medical procedure, and the health care committee would assume responsibility for arranging medical audits, in the first instance on an experimental basis. Dr. D. H. Irvine in today's Supplement (p. 39) discusses the difficulties inherent in introducing checks into traditional areas of professional independence. Professor Dollery's proposals are controversial but they indicate one pathway to a coherent philosophy and clear objectives for the Health Service. While medical science has raced ahead with new discoveries leading to fresh and very often expensive treatments, the organization necessary for deciding which new treatment should be generally introduced and which used on an experimental basis, or even rejected, has fallen sadly behind.

In addition to this issue the essays range over many other topics such as consultant organization (with a special look at regional consultants), information systems, com- 
munity medicine, general practice, health organization at local levels, and staffing problems. They deserve to be widely read, and the initiative of the Nuffield Provincial Hospitals Trust in commissioning them is welcome.

The new shape of the N.H.S. is far from settled and the health professions must make sure that in the reshaped N.H.S. their concerted views, based on thorough research, are continuously available to local and central health authorities. The Department of Health rightly attaches importance to preserving clinical freedom, but it hopes that doctors will exercise this freedom "in the knowledge of the available resources and of national and local priorities and objectives." If the profession can do this its claim to a bigger share of national resources for the N.H.S. will carry more weight.

1 Department of Health and Social Security, National Health Service Reorganization, Consultative Document. London, 1971.

2 Welsh Office, National Health Service Reorganization in Wales, Consultative Document. June 1971.

3 Reorganization of the Scottish Health Services, Cmnd. 4734. Edinburgh H.M.S.O., 1971.

4 Government of Northern Ireland, The Administrative Structure of the Health and Personal Social Services in Northern Ireland. Belfast the Health and Pers
H.M.S.O. 1969 .

5 Challenges for Change, Essays on the Next Decade in the National Health Service. Commissioned by Nuffield Provincial Hospitals Trust, Oxford University Press, 1971.

6 The Expenditure Committee (Employment and Social Services Subcommittee) Minutes of Evidence, 323-ii. London, H.M.S.O., 1971.

\section{Herpetic Whitlow: A Medical Risk}

Septic fingers are a common cause of attendance at doctors' surgeries. They are nearly always due to Staphylococcus aureus, but some-especially those acquired by nurses and doctors-may be caused by herpes simplex virus. ${ }^{1-7}$

The main sites of this form of herpes, which is known as herpetic whitlow, are the distal segments of the fingers, of which the thumbs and forefingers are most of ten involved. At first glance the lesions can easily be mistaken for staphylococcal infections, but there are a few clues which indicate their viral origin. The earliest sign of infection is an area of tenderness and erythema in which small vesicles soon appear. These enlarge and may coalesce to form a large vesicle, which is typically surrounded by a bright border of erythema. Sometimes secondary vesicles appear in the surrounding skin. The vesicle fluid is serous rather than purulent and creamy as in bacterial infection. The lesions are usually extremely painful, and the patient complains of throbbing-which is often severe-in the affected finger. Fever, lymphadenitis, and lymphangitis are seen in a few patients, but the majority do not have any constitutional disturbance. After about ten days the pain subsides and the vesicles start to dry up with crust formation and some desquamation of the superficial layers of the skin. Healing is usually complete, and the course of the infection lasts from two and a half to three weeks. Though most herpetic whitlows are primary infections, in a few patients the infection becomes recurrent at the site of the original lesion. ${ }^{1} 28$

Most of the cases reported have been in doctors or nurses, and the main source of infection seems to be the oropharyngeal secretions of patients-especially if they have a tracheostomy. The route of infection appears to be by contamination of minor cuts and breaks in the skin by virus-containing secretions. In their classic description of the disease H. Stern and colleagues ${ }^{2}$ found that herpes simplex virus was present in the bronchial secretions of $6.5 \%$ of patients with tracheostomies compared to an incidence of only $1.2 \%$ in the saliva of unselected patients on admission. Nurses in neurosurgical units are particularly liable to develop herpetic whitlow, and the infection sometimes takes the form of small outbreaks there. Among doctors infection is most common in surgeons and anaesthetists.

Herpes simplex virus does not infect by direct inoculation people who have herpes antibody. Since the incidence of herpes antibody in young adults is about $70 \%$ and rises steadily with increasing age, it follows that most people are immune to this form of infection. The incidence of herpes antibody among students and nurses is lower than in the general population, because they are younger. For example, more than half of the students and nurses examined in Edinburgh and Oxford by I. W. Smith, J. F. Peutherer, and F. O. MacCallum were found to be non-immune to herpes simplex. ${ }^{9}$ This fact, together with the increased risk of exposure to infection in certain kinds of medical unit, explains why these infections are mainly seen in doctors and nurses.

Herpetic whitlow should be treated conservatively with a dry dressing applied to the lesions and administration of analgesics for the pain. Surgical intervention is to be avoided unless there is considerable tension, when a simole incision may help to reduce pain. Idoxuridine apolied locally in the form of a $5 \%$ solution in dimethyl sulrhoxide reduces the duration of the lesions in herpetic infection of the face, ${ }^{10}$ and it may have a similar beneficial effect on herpetic whitlow. In a few patients the lesions become superinfected with Staphylococcus aureus, and in these circumstances antibiotics may be prescribed, though they naturally have no effect on the course of the viral infection.

1 Adamson, H. G., British Fournal of Dermatology, 1909, 21, 323.

2 Stern, H., Elek, S. D., Millar, D. M., and Anderson, H. F., Lancet, 1959 2, 871 .

Ward, J. R., and Clark, L., Fournal of the American Medical Association, $1961,176,226$ Hambrick, G. W., Cox, R. P., and Senior, J. R., Archives of Dermatology,
1962, 85, 583.

${ }^{5}$ Kanaar, P., Dermatologica, 1967, 134, 346.

6 Orkin, F. K., Anesthesiology, 1970, 33, 671.

7 LaRossa, D., and Hamilton, R., Archives of Surgery, 1971, 102, 600. Trice, E. R., and Shafer, J. C., Archives of Dermatology and Syphilology,
1953, 67, 37.

${ }^{9}$ Smith, I. W., Peutherer, J. F., and MacCallum, F. O., Fournal of Hygiene. 1967, 65, 395 . ${ }^{10}$ MacCallum, F. O., and Juel-Jensen, B. E., British Medical fournal, 1966,

\section{Pregnancy Testing}

One of the inevitable outcomes of greater sexual freedom in our society has been a sharp increase in the demand for pregnancy testing. As recent correspondence in the B.M.F. has shown, this has placed an additional strain on general practitioners and hospital laboratories alike. The delays sometimes encountered in getting a test result have led to the growth of private laboratories offering this service, which have been allowed to advertise it since the change in attitude by the Advertising Standards Authority in 1966. Despite this, however, the profession's attitude has always been clear. Firstly, whether these laboratories provide direct access to the public or serve the doctor they should be directed 